\title{
Delirium Severity and Correlates among Medical Inpatients Admitted through Accident and Emergency Unit of Jos University Teaching Hospital
}

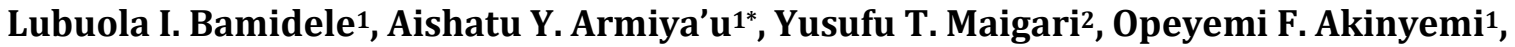 \\ Taiwo J. Obindo ${ }^{2}$
}

${ }^{1}$ Department of Psychiatry, Jos University Teaching Hospital, Jos, Nigeria

${ }^{2}$ Department of Psychiatry, University of Jos/Jos University Teaching Hospital, Jos, Nigeria

Email: *aarmiyau@gmail.com

How to cite this paper: Bamidele, L.I., Armiya'u, A.Y., Maigari, Y.T., Akinyemi, O.F. and Obindo, T.J. (2018) Delirium Severity and Correlates among Medical Inpatients Admitted through Accident and Emergency Unit of Jos University Teaching Hospital. Open Journal of Emergency Medicine, 6, 31-42.

https://doi.org/10.4236/ojem.2018.63006

Received: June 13, 2018

Accepted: August 10, 2018

Published: August 13, 2018

Copyright $\odot 2018$ by authors and Scientific Research Publishing Inc. This work is licensed under the Creative Commons Attribution International License (CC BY 4.0).

http://creativecommons.org/licenses/by/4.0/

\section{(c) (i) Open Access}

\begin{abstract}
Background: Delirium is one of the most common medical emergencies and is associated with poor outcomes including: mortality, prolonged length of stay and poor functional outcome. The more severe delirium is the worst the clinical outcomes of medical illness. Despite the obvious, not much has been documented on delirium severity and its associated factors among medical inpatients in low income countries including Nigeria. Objectives: This study was conducted to examine the severity of delirium among medical inpatients admitted through the Accident and Emergency unit of Jos University Teaching Hospital as well as to assess its associated Sociodemographic and Clinical characteristics. Method: This was a cross-sectional study that employed a consecutive sampling technique to select 290 eligible subjects from medical inpatients that presented to Accident and Emergency unit of Jos University Teaching Hospital. On admission, patients were assessed for delirium using Confusion Assessment Method and severity of delirium was evaluated using Delirium Rating Scale-Revised-98. Results: Of the 105 delirious medical inpatients, 48 (45.7\%) had severe delirium, 41 (39.1\%) developed less severe delirium while 16 (15.2) presented with no severe delirium. Sociodemographic characteristics found to be significantly associated with less to more severe delirium include male gender $(P=0.001)$, nonprofessionals $(P=0.003)$, income range of $\mathrm{N} 20,000-\mathrm{N} 49,000(\mathrm{P}<0.001)$ and being married $(\mathrm{P}=0.022)$. However, prior cognitive impairment was found to be significantly associated with severe delirium $(\mathrm{P}<0.001)$. Conclusion: This study demonstrates that delirium is often associated with higher severity in Accident and Emergency
\end{abstract}


unit admission and there are strongly associated clinical characteristics to watch out for in high risk medical inpatients.

\section{Keywords}

Delirium Severity, Medical Inpatients, Sociodemographic and Clinical Characteristics, Accident and Emergency Unit

\section{Introduction}

The Diagnostic and Statistical Manual of Mental disorders, $5^{\text {th }}$ edition (DSM5) defined delirium as an acute onset of fluctuating cognitive impairment and a disturbance of consciousness which is characterized by disturbances of orientation, memory, language skills, thinking, perception, motor behavior, sleep wake cycle and with impaired attention as the core cognitive disturbance that is not better explained by a pre-existing, established or other evolving neurocognitive disorders [1]. It is associated with several adverse outcomes which include more prolonged hospitalization, mortality and institutionalization that is even more worrisome in low income countries [2] [3]. A wide range of delirium prevalence has been reported in several studies from developed to developing countries in the range of $9 \%-32 \%$ emphasizing how common delirium is among medical inpatients [4] [5] [6]. Studies have also established negative impact of delirium on clinical outcomes such as length of stay, mortality and other complications [7] [8] [9]. For instance, Inuoye et al. [9] found delirium to be an important independent prognostic determinant of hospital outcomes including death, nursing home placement and functional decline even after controlling for age, gender, dementia, illness severity and functional status.

Moreover, a smaller but growing bodies of literature have reported that prognosis of delirium is even worst among patients with severe delirium [10] [11]. In addition, it may be difficult to prevent delirium in patients due to influence of underlying pathology, the need for evidence based treatment strategies that reduce severity of delirium in medical inpatients is critical and rests on a more informed understanding of delirium severity and its associated factors.

Considering close relationship between delirium and certain clinical characteristics [12] [13], we expected that there may be more important clinical characteristics associated with higher delirium severity.

As a matter of fact, no study has examined the magnitude of delirium severity and associated characteristics among medical inpatients at Accident and Emergency (A \& E) setting in Nigeria. Consequently, this study aimed at assessing the occurrence of delirium severity at A \& E and also evaluates its associated factors for a better risk prediction in high risk medical inpatients.

\section{Methodology}

This hospital based cross-sectional study was conducted at the A \& E unit of Jos 
University Teaching Hospital (JUTH) and Medical wards between the months of July and November 2016. The study aimed at determining the severity of delirium among medical inpatients admitted through the Accident and Emergency unit of Jos University Teaching Hospital as well as assessing its associated Sociodemographic and Clinical characteristics. Data were collected by the researcher and research assistants who are fluent in both English and Hausa languages.

The study employed a consecutive sampling technique to select medically ill adults aged 18 years and above, admitted through the A\&E within 24 hours and consented to participate in the study either by themselves or through their relatives. The rationale for the 24 hours limit was to maximize the number of patients that could be enrolled, while minimizing the patients' exposure to multiple delirium precipitants such as immobilization, bladder catheter placement or any iatrogenic event [14]. On the other hand, eligible respondents who were deeply unconscious with surgical comorbidities and diagnoses of schizophrenia or mood disorders were excluded from the study.

The socio-demographic questionnaire was administered first and this sought information on socio-demographic data (age, gender, level of education, occupation, estimated monthly income and marital status) and clinical variables such as past year substance use, current medication, past history of mental illness, prior cognitive and physical impairments, illness duration before presentation and medical diagnosis.

Confusion Assessment Method (CAM) was thereafter administered on those who were fit to participate in the study so as to assess for delirium. Only those diagnosed with delirium using CAM were subsequently administered a Delirium Rating Scale-Revised-98 (DRS-R-98) on alternate day basis until point of discharge or death in order to identify average severity score of delirium in each delirious participant. Participants identified with Delirium were discussed with managing medical team for possible co-management with our ConsultationLiaison team for effective management.

DRS-R-98 is a 16-item observational clinician rated scale with a maximum total severity score of 39 points and total diagnostic score of 46 points. It has two sections: the first is a 13 -item severity scale that is used for repeated measurement within an episode of established delirium. The other section, consisting of three items, focuses on features related to the diagnostic features of delirium. The thirteen severity items are rated 0 - 3 while the three diagnostic items are rated 0 - 3 for the first item, then 0 - 2 for the other two items. Score of $\geq 12$ points represent full syndrome delirium. The severity ratings range from 0 (no impairment) to 3 (severe impairment) and a severity score is $>15$ points; depicting 12 - 15 (no severe delirium), 16 - 20 (less severe delirium), above 20 (severe delirium). The respondents in this study were followed up till point of discharge or death. Average inpatient stay as observed from this study was 18 days.

It is worthy of note that both instruments (CAM and DRS-R-98) have been used successfully in Nigeria [6] [15]. 
The Statistical Package for Social Sciences Version 21 (SPSS-21) software package was used to analyze the data.

\section{Results}

A total of 302 respondents were interviewed, but 290 (96\%) interviews were used in the analysis. The remaining 12 were excluded because of incomplete data.

The age range of the respondents was between 22 and 100 years and their mean age was $46.2 \pm 17.2$ years, with more than half $(56.6 \%)$ of them been females.

The ethnic distribution of the sample comprised Berom 60 (20.7\%), Hausa/Fulani 25 (12.1\%), and other ethnic minorities; 195 (67.2\%) such as Tarok, Mughavul, Angas, Miango, Ibo, Yoruba, Irigwe, Jukun, Ijaw, Idoma and Tiv. Respondents were predominantly Christians 244 (84.1\%) while the rest were Muslims 46 (15.9\%)

Of the 290 respondents, 208 (71.7\%) had below tertiary level of education, 193 (66.5\%) were employed and largely nonprofessional occupation group, and majority 269 (92.7\%) had their income below N50,000.00. With respect to marital distribution, more than half were married 165 (56.9\%). The rest 135 (43.1\%) were unmarried comprising those never married, previously married (divorced or separated), and widowed.

Among the respondents, only 14 (4.8\%), 34 (11.7\%) and 24 (8.3\%) had previous history of mental illness, preexisting cognitive decline and physical impairment respectively.

Out of the 290 respondents, 183 (63.19\%) had been medically ill for less than 2 weeks while the rest had been ill for at least 2 weeks before presentation. Among the respondents, 89 (30.7\%) each were on regular antibiotics and other medications (Steroids, Cytotoxic, Antiretroviral drugs etc). The rest 112 (38.6\%) were either on anti-kocks, oral hypoglycemic or antihypertensive (Table 1). Concerning medical diagnosis; 140 (48.3\%) had infectious diseases, 52 (17.9\%) had organ failures, while the rest, 78 (33.8\%) had poor glycemic control, cerebrovascular disease (CVD) and other medical illnesses (Figure 1).

More than two-third were abstainers. Among those currently using substance, alcohol was the most preferred substance (20.34\%), while only $3.45 \%$ and $1.72 \%$ were multiple substance users/other substance respectively (Figure 2).

Among the 290 participants assessed for delirium, only 105 (35.9\%) had delirium; of this, 48 (45.7\%) had severe delirium, 41 (39.1\%) were found with less severe delirium while 16 (15.2) presented with no severe delirium.

A higher proportion of the male participant 53 (50.5\%) developed less severe to severe delirium compared to their female counterparts at a statistically significant level $(\mathrm{P}=0.022)$, so also was a higher proportion recorded among Nonprofessionals $50(47.6 \%)$ and married respondents $60(57.1 \%)$ compared to their professional $23(21.9 \%)$ and Never married 12 (11.4\%) counterparts respectively at statistically significant levels $(\mathrm{P}=0.001, \mathrm{P}=0.003)$. Participants who earned 
Table 1. Socio-demographic and clinical characteristics of respondents at the time of study.

\begin{tabular}{|c|c|c|c|}
\hline Variables & Responses & Frequency (n) & Percentage (\%) \\
\hline \multirow[t]{4}{*}{ Age (years) } & $18-34$ & 118 & 40.7 \\
\hline & $35-64$ & 125 & 43.1 \\
\hline & $65-100$ & 47 & 16.2 \\
\hline & Mean \pm SD $(46.22 \pm 17.24)$ & & \\
\hline \multirow[t]{2}{*}{ Gender } & Male & 126 & 43.4 \\
\hline & Female & 164 & 56.6 \\
\hline \multirow[t]{3}{*}{ Ethnicity } & Berom & 60 & 20.7 \\
\hline & Hausa/Fulani & 35 & 12.1 \\
\hline & ${ }^{\star}$ Others & 195 & 67.2 \\
\hline \multirow[t]{2}{*}{ Religion } & Christianity & 244 & 84.1 \\
\hline & Islam & 46 & 15.9 \\
\hline \multirow[t]{4}{*}{ Educational status } & No formal education & 22 & 7.6 \\
\hline & Primary education & 94 & 32.4 \\
\hline & Secondary education & 92 & 31.7 \\
\hline & Tertiary education & 82 & 28.3 \\
\hline \multirow[t]{3}{*}{ Occupational status } & Professionals (1 - 11) & 70 & 24.1 \\
\hline & Nonprofessionals (111 - V) & 123 & 42.4 \\
\hline & Unemployed (V1) & 97 & 33.5 \\
\hline \multirow[t]{3}{*}{ Estimated monthly income } & $<20,000.00$ & 150 & 51.7 \\
\hline & $20,000.00-49,000.00$ & 119 & 41.0 \\
\hline & $\geq 50,000.00$ & 21 & 7.3 \\
\hline \multirow[t]{4}{*}{ Marital status } & Never married & 71 & 24.5 \\
\hline & Married & 165 & 56.9 \\
\hline & Previously married & 7 & 2.4 \\
\hline & Widowed & 47 & 16.2 \\
\hline \multirow[t]{2}{*}{ Mental illness history (Past) } & Yes & 14 & 4.8 \\
\hline & No & 276 & 95.2 \\
\hline \multirow[t]{2}{*}{ Prior cognitive decline } & Yes & 34 & 11.7 \\
\hline & No & 256 & 88.3 \\
\hline \multirow[t]{2}{*}{$\begin{array}{c}\text { Preexisting } \\
\text { physical impairment }\end{array}$} & Yes & 24 & 8.3 \\
\hline & No & 266 & 91.7 \\
\hline \multirow[t]{3}{*}{$\begin{array}{l}\text { Illness duration } \\
\text { before presentation }\end{array}$} & $<2$ weeks & 183 & 63.1 \\
\hline & 2 - 4 weeks & 72 & 24.8 \\
\hline & $>4$ weeks & 35 & 12.1 \\
\hline \multirow[t]{5}{*}{ Current Medication } & Regular antibiotics & 89 & 30.7 \\
\hline & Antikock's & 54 & 18.6 \\
\hline & Oral hyoglyceamic/insulin & 27 & 9.3 \\
\hline & Antihypertensive & 31 & 10.7 \\
\hline & Others & 89 & 30.7 \\
\hline
\end{tabular}

*Others: Tarok 21 (10.8\%), Mughavul 22 (11.2\%), Angas 20 (10.3\%), Miango 20 (10.3\%), Ibo 19 (9.7\%), Yoruba 21 (10.8\%), Irigwe 12 (6.2\%), Jukun 9 (4.5\%), Ijaw10 (5.1\%), Idoma 20 (10.3\%) and Tiv 21 (10.8\%). 


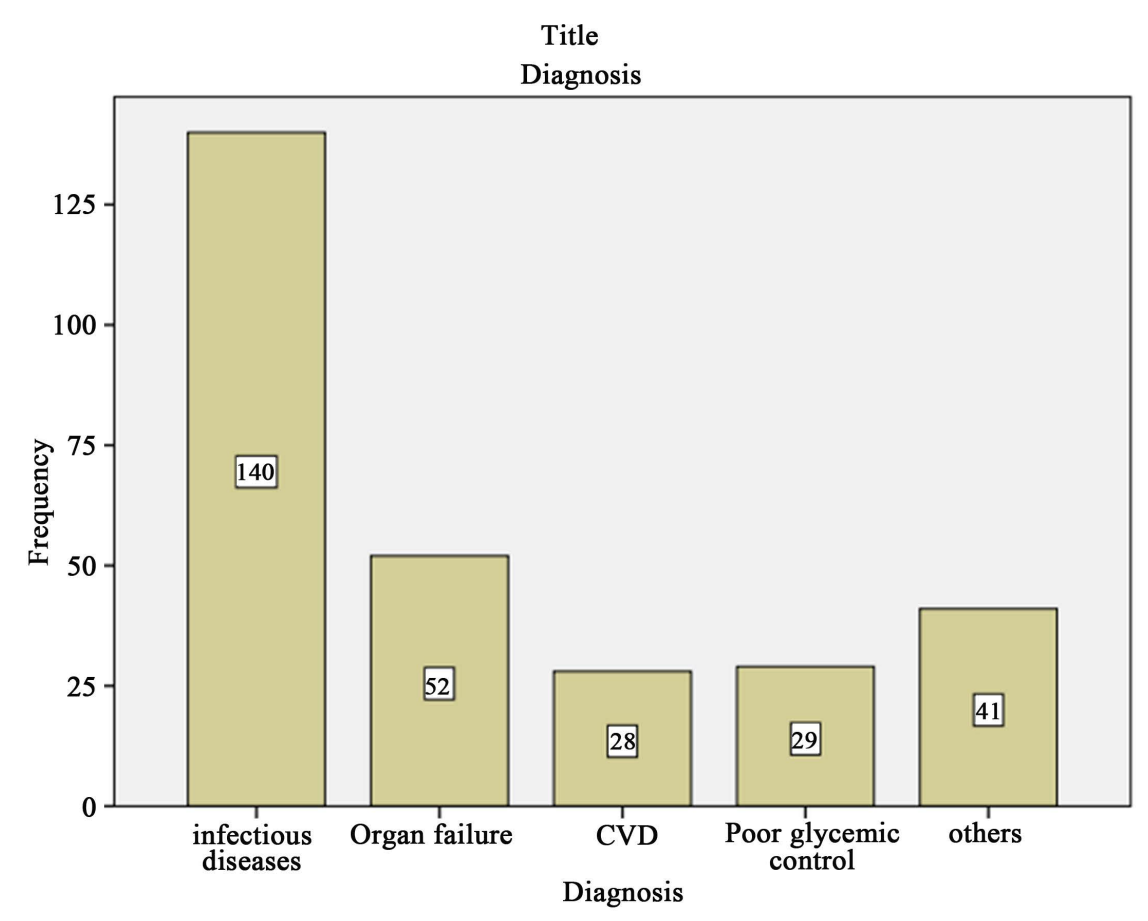

Figure 1. Distribution of Respondents according to current medical diagnoses.

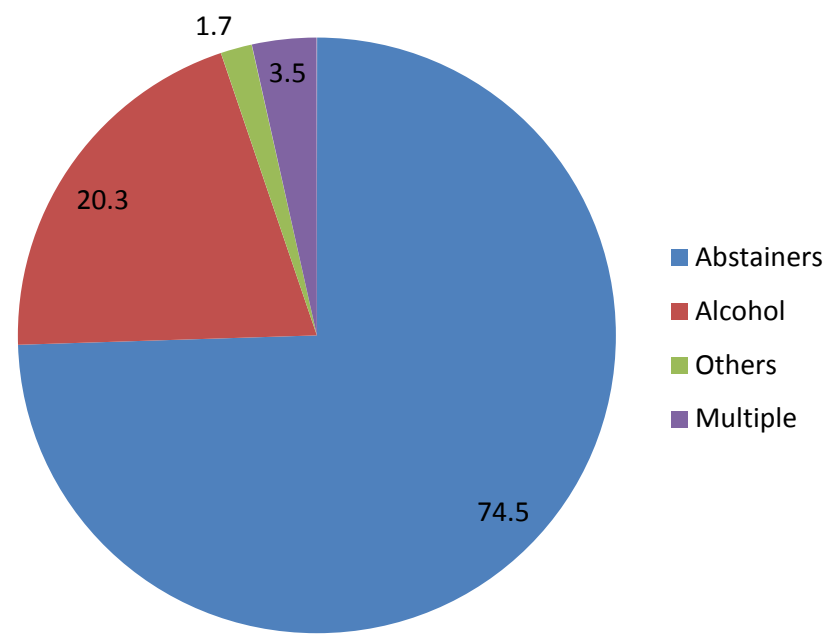

Figure 2. Distribution of respondents according to type of substance use (percentage).

estimated monthly income between 20,000 - 49,000 were more likely to develop less severe to severe delirium compared to their respective counterparts at statistically significant level $\mathrm{P}<0.001$ ) (Table 2).

Majority of the respondents who presented less than 2 weeks of illness onset (80.5\%), with a diagnosis of infectious diseases $(61.0 \%)$ and placed on regular antibiotics (46.3\%) were significantly more likely to develop less severe delirium compared to their respective counterparts $(\mathrm{P}<0.001, \mathrm{P}<0.001 \& \mathrm{P}=0.001)$. Similarly, there was a significant relationship between prior cognitive impairment and delirium severity with respondents with prior cognitive impairment more likely to develop severe delirium $(\mathrm{P}<0.001)$. Similarly, a higher proportion 
Table 2. Socio-demographic characteristics of respondents based on delirium severity.

\begin{tabular}{|c|c|c|c|c|c|c|c|}
\hline \multirow{3}{*}{ Variables } & \multirow{2}{*}{\multicolumn{4}{|c|}{$\begin{array}{c}\text { Severity of Delirium } \\
\text { No severe Less Severe Severe }\end{array}$}} & \multirow{2}{*}{\multicolumn{3}{|c|}{ Statistics }} \\
\hline & & & & & & & \\
\hline & n (\%) & n (\%) & n (\%) & Total N (\%) & $\mathrm{X}^{2}$ & $\mathrm{df}$ & $\mathbf{P}$ \\
\hline \multicolumn{8}{|l|}{ Age } \\
\hline $18-34$ & $89(44.3)$ & $14(34.1)$ & $15(31.2)$ & $118(40.7)$ & 9.421 & 4 & 0.51 \\
\hline $35-64$ & $84(41.8)$ & $22(53.7)$ & 19 (39.6) & $125(43.1)$ & & & \\
\hline $65-100$ & $28(13.9)$ & $5(12.2)$ & $14(29.2)$ & $47(16.2)$ & & & \\
\hline \multicolumn{8}{|l|}{ Gender } \\
\hline Male & $73(36.3)$ & $27(65.9)$ & $26(54.2)$ & $126(43.4)$ & 14.779 & 2 & 0.001 \\
\hline Female & $128(63.7)$ & $14(34.1)$ & $22(45.8)$ & $164(56.6)$ & & & \\
\hline \multicolumn{8}{|l|}{ Ethnicity } \\
\hline Berom & $40(19.9)$ & $14(34.1)$ & $6(12.5)$ & $60(20.7)$ & 9.772 & 4 & 0.044 \\
\hline Hausa/Fulani & $29(14.4)$ & $2(4.9)$ & $4(8.3)$ & $35(12.1)$ & & & \\
\hline Others & $132(65.7)$ & $25(61.0)$ & $38(79.2)$ & $195(67.2)$ & & & \\
\hline \multicolumn{8}{|l|}{ Religion } \\
\hline Christianity & $166(82.6)$ & $37(90.2)$ & $41(85.4)$ & $244(84.1)$ & 1.566 & 2 & 0.457 \\
\hline Islam & $35(17.4)$ & $4(9.8)$ & $7(14.6)$ & $46(15.9)$ & & & \\
\hline \multicolumn{8}{|l|}{ Educational status } \\
\hline No formal education & $13(6.5)$ & $5(12.1)$ & $4(8.3)$ & $22(7.6)$ & 7.042 & 6 & $0.280^{*}$ \\
\hline Primary education & $64(31.9)$ & $12(29.3)$ & $18(37.5)$ & $94(32.4)$ & & & \\
\hline Secondary education & $61(30.3)$ & $12(29.3)$ & $19(39.6)$ & $92(31.7)$ & & & \\
\hline Tertiary education & $63(31.3)$ & $12(29.3)$ & $7(14.6)$ & $82(28.3)$ & & & \\
\hline \multicolumn{8}{|l|}{ Occupational status } \\
\hline Professionals \pm degree (I - II) & $47(23.4)$ & $12(29.3)$ & $11(22.9)$ & $70(24.1)$ & 15.944 & 4 & 0.003 \\
\hline Nonprofessionals (III - V) & $73(36.3)$ & $21(51.2)$ & $29(60.4)$ & $123(42.4)$ & & & \\
\hline Unemployed (VI) & $81(40.3)$ & $8(19.5)$ & $8(16.7)$ & $97(33.5)$ & & & \\
\hline \multicolumn{8}{|l|}{ Estimated income/month } \\
\hline$<20,000.00$ & $118(58.7)$ & $10(24.4)$ & $22(45.8)$ & $150(51.7)$ & 20.688 & 4 & $<0.001^{*}$ \\
\hline $20,000.00-49,000.00$ & $73(36.3)$ & $23(56.1)$ & $23(47.9)$ & $119(41.0)$ & & & \\
\hline$\geq 50,000.00$ & $10(5.0)$ & $8(19.5)$ & $3(6.3)$ & $21(7.3)$ & & & \\
\hline \multicolumn{8}{|l|}{ Marital status } \\
\hline Never married & $59(29.4)$ & $6(14.6)$ & $6(12.5)$ & $71(24.5)$ & 13.990 & 6 & 0.022 \\
\hline Married & $105(52.2)$ & $30(73.2)$ & $30(62.5)$ & $165(56.9)$ & & & \\
\hline Previously married & $4(2.0)$ & $0(0.0)$ & $3(6.3)$ & $7(2.4)$ & & & \\
\hline Widowed & $33(16.4)$ & $5(12.2)$ & $9(18.7)$ & $47(16.2)$ & & & \\
\hline
\end{tabular}

* = Likelihood Ratio. 
of non-users of psychoactive substance developed less severe (53.7\%) to severe (70.8\%) delirium at a statistically significant level compared to those that were users $(\mathrm{P}<0.001)$ (Table 3$)$.

\section{Discussion}

This study found socio-demographic variables such as gender, occupation,

Table 3. Clinical characteristics of respondents based on delirium severity.

\begin{tabular}{|c|c|c|c|c|c|c|c|}
\hline \multirow{3}{*}{ Variables } & \multicolumn{4}{|c|}{ Severity of Delirium } & \multirow{2}{*}{\multicolumn{3}{|c|}{ Statistics }} \\
\hline & \multirow{2}{*}{$\begin{array}{c}\text { No severe } \\
\mathrm{n}(\%)\end{array}$} & \multirow{2}{*}{$\begin{array}{c}\text { Less severe } \\
\text { n (\%) }\end{array}$} & \multirow{2}{*}{$\begin{array}{l}\text { Severe } \\
\text { n (\%) }\end{array}$} & \multirow{2}{*}{$\begin{array}{l}\text { Total } \\
\text { N (\%) }\end{array}$} & & & \\
\hline & & & & & $\mathrm{X}^{2}$ & df & $\mathrm{P}$ \\
\hline \multicolumn{8}{|l|}{ Current medication } \\
\hline Regular antibiotics & $62(30.8)$ & $19(46.3)$ & $8(16.7)$ & $89(30.7)$ & 26.825 & 8 & 0.001 \\
\hline Anti-kock's & $23(11.4)$ & $0(0.0)$ & $8(16.7)$ & $31(10.7)$ & & & \\
\hline Oral hypoglycemic/insulin & $21(10.4)$ & $0(0.0)$ & $6(12.5)$ & $27(9.3)$ & & & \\
\hline Antihypertensive & $33(16.4)$ & $10(24.4)$ & $11(22.9)$ & $54(18.6)$ & & & \\
\hline Others & $62(30.8)$ & $12(29.3)$ & $15(31.3)$ & $89(30.7)$ & & & \\
\hline \multicolumn{8}{|l|}{ Past-year substance use/type } \\
\hline Nonusers & $160(97.6)$ & $22(53.7)$ & $34(70.8)$ & $216(74.5)$ & 24.888 & 6 & $<0.001^{*}$ \\
\hline Alcohol & $37(18.4)$ & $13(31.7)$ & $9(18.8)$ & $59(20.3)$ & & & \\
\hline $\begin{array}{c}\text { Multiple } \\
\left(\text { alcohol, tramadol, } \mathrm{BDZ}^{*}\right)\end{array}$ & $1(0.5)$ & $4(9.8)$ & $5(10.4)$ & $10(3.4)$ & & & \\
\hline Others & $3(1.5)$ & $2(4.9)$ & $0(0.0)$ & $5(1.7)$ & & & \\
\hline \multicolumn{8}{|l|}{ Mental illness history } \\
\hline Yes & $10(5.0)$ & $2(4.9)$ & $2(4.2)$ & $14(4.8)$ & 0.057 & 2 & $0.972^{*}$ \\
\hline No & $191(95.0)$ & $39(95.1)$ & $46(95.8)$ & $276(95.2)$ & & & \\
\hline \multicolumn{8}{|l|}{ Prior cognitive impairment } \\
\hline Yes & $15(44.1)$ & $4(11.8)$ & $15(44.1)$ & $34(100)$ & 21.363 & 2 & $<0.001^{*}$ \\
\hline No & $186(72.7)$ & $37(14.4)$ & $33(12.9)$ & $256(100)$ & & & \\
\hline \multicolumn{8}{|l|}{ Physical impairment } \\
\hline Yes & $20(10.0)$ & $0(0.0)$ & $4(8.3)$ & $24(8.3)$ & 7.785 & 2 & $0.020^{\star}$ \\
\hline No & $181(90.0)$ & $41(100.0)$ & $44(91.7)$ & $266(91.7)$ & & & \\
\hline \multicolumn{8}{|l|}{$\begin{array}{l}\text { Illness duration } \\
\text { before presentation }\end{array}$} \\
\hline$<2$ weeks & $128(63.7)$ & $33(80.5)$ & $22(45.8)$ & $183(63.1)$ & 21.664 & 4 & $<0.001^{\star}$ \\
\hline $2-4$ weeks & $51925.4)$ & $8(19.5)$ & $13(27.1)$ & $72(24.8)$ & & & \\
\hline$>4$ weeks & $22(10.9)$ & $0(0.0)$ & $13(27.1)$ & $35(12.1)$ & & & \\
\hline \multicolumn{8}{|l|}{ Medical diagnosis } \\
\hline Infectious diseases & $99(49.3)$ & $25(61.0)$ & $16(33.3)$ & $140(48.3)$ & 29.470 & 8 & $<0.001^{*}$ \\
\hline $\begin{array}{c}\text { Organ failures } \\
\text { (CLD, CKD \& HHD) }\end{array}$ & $28(13.9)$ & $10(24.4)$ & $14(29.2)$ & $52(17.9)$ & & & \\
\hline Cerebrovascular disease & $18(9.0)$ & $2(4.9)$ & $8(16.7)$ & $28(9.7)$ & & & \\
\hline Poor glycemic control & $21(10.4)$ & $0(0.0)$ & $8(16.7)$ & $29(10.0)$ & & & \\
\hline Others & $35(17.4)$ & $4(9.8)$ & $2(4.2)$ & $41(14.1)$ & & & \\
\hline
\end{tabular}

* = Likelihood Ratio. 
marital status and income to be significantly associated with delirium severity, while clinical variables observed to be significantly associated with delirium severity include: Abstainers from psychoactive substance, prior cognitive decline, hospital presentation of less than 2 weeks of illness onset and diagnosis of infectious diseases.

The finding that males rather than their female counterparts were more likely to develop delirium severity is in keeping with previous study [11]. Females may have had a historical advantage with respect to building cognitive reserve against brain vulnerability i.e. greater education and occupational achievement [11]. So also is the fact that Females compared to the males may gain resistance to higher delirium severity through efforts that increase physical health and prevent high comorbidity and resultant frailty [16]. This also lends credence to the fact that more severe delirium was observed in the less educated non-professional respondents with estimated income level below N50, 000. Education has historically been a proxy for cognitive reserve; education and other mentally stimulating activity is thought to build reserve both by increasing synaptic connection and density as well as by developing the ability to use alternate strategies for circumventing brain pathology [11].

This study observed that, aside from increasing the risk of delirium, prior cognitive decline was also found to be associated with delirium severity. The result corroborates previous observations [10] [11] [17]. Mercantio et al. [10] observed that patients with prior cognitive impairment were more likely to develop severe delirium due to low cognitive reserve and generalised decline in brain adaptivity. Furthermore, severe comorbidities from infectious diseases with a stronger acuity of illness presentation within 2 weeks may likely to increase the persistence of delirium symptoms and hence its severity [11] [17].

It is worthy of note that a high proportion of non-users of psychoactive substance developed less severe delirium as they largely had diagnoses of infectious diseases and organ failure which have also been both associated with delirium severity [11].

Less severe delirium was found more in respondents on antibiotics who perhaps developed more severe delirium on presentation but gradually had their symptoms resolved from severe to a less severe form of delirium after commencement of antibiotics.

\section{Conclusion}

This study established that delirium in its severe form is a common observation among medical inpatients admitted through the Accident and Emergency unit. More often than not, it is associated with certain Sociodemographic and clinical characteristics which could be a pointer of prediction in high risk patient developing delirium and hence, the need for assessment. This study has implications not only in the prevention of needless deaths associated with delirium but also identifying people who have greatest need for early intervention to reduce the far 
reaching negative impacts of severe delirium.

\section{Acknowledgements}

We appreciate management of Jos University Teaching Hospital and paramedics in the Accident and Emergency Unit for the assistance rendered towards actualization of this research.

\section{Ethical Approval and Consent to Participate}

Ethical approval was obtained and granted by the ethical committee of Jos University Teaching Hospital Institutional Health Research Committee, marked reference number (JUTH/DCS/ADM/127/XIX/6564), while permissions were also granted by the heads of Internal Medicine and A \& E unit. All participants signed or thumb printed for informed consent before study.

\section{Availability of Data and Materials}

Please contact Authors for Data requests.

\section{Competing Interests}

No competing interests declared for this study.

\section{Funding}

This research did not receive any specific grant from funding agencies in the public, commercial, or non-profit sectors.

\section{Authors' Contributions}

LIB and AYA conceived the original idea. LIB, AYA, YTM, OFA, FPT and TJO designed the study. LIB, AYA and OFA collected data. LIB, YTM, FPT and TJO analyzed and interpreted data. LIB, AYA, YTM, OFA, and FPT prepared the first manuscript. All authors contributed significantly and critically to final manuscript.

\section{References}

[1] American Psychiatric Association (2013) Diagnostic and Statistical Manual of Mental Disorders, Fifth Edition. 5th Edition, American Psychiatric Association, Washington, DC, 594-560.

[2] Grover, S., Kate, N., Agarwal, M. and Mattoo, S.K. (2012) Delirium in Elderly People: A Study of a Psychiatric Liaison Service in North India. International Psychogeriatrics, 24, 117-127. https://doi.org/10.1017/S1041610211001815

[3] Sri-on, J., Tirrell, G.P., Vanichkulbodee, A., Niruntarai, S. and Liu, S.W. (2016) The Prevalence, Risk Factors and Short-Term Outcomes of Delirium in Thai Elderly Emergency Department. Emergency Medicine Journal, 33, 17-22. https://doi.org/10.1136/emermed-2014-204379

[4] Han, J.H., Zimmerman, E.E., Cutler, N., Schnelle, J., Alessandro, M., Dittus, R.S., et al. (2009) Delirium in Older Emergency Department Patients: Recognition, Risk 
Factors, and Psychomotor Subtypes. Academic Emergency Medicine, 16, 193-200. https://doi.org/10.1111/j.1553-2712.2008.00339.x

[5] Paddick, S.M., Gray, W.K., Mbowe, G., Dotchin, C., Kisima, J., Lwezaula, F., et al. (2015) Prevalence of Delirium in Older Hospitalized Adults in Tanzania. Journal of Neurology, Neurosurgery and Psychiatry, 86, e3. https://doi.org/10.1136/jnnp-2015-311750.29

[6] Ajiboye, P.O. and Adelekan, M.L. (2004) A Prospective Analysis of In-Patient Consultation Liaison Psychiatry in a Nigeria Teaching Hospital. East African Medical Journal, 81, 620-625.

[7] Siddiqi, N., House, A.O. and Holmes, J.D. (2006) Occurrence and Outcome of Delirium in Medical Inpatients: A Systematic Literature Review. Age Ageing, 35, 350-364. https://doi.org/10.1093/ageing/afl005

[8] Mariz, J., Santos, S.C. and Afonso, H. (2013) Risk and Clinical Outcome Indicators of Delirium in an Emergency Department Intermediate Care Unit (EDIMCU): An Observational Prospective Study. BMC Emergency Medicine, 13, 2-8. https://doi.org/10.1186/1471-227X-13-2

[9] Inuoye, S.K., Rushing, J.T., Foreman, M.D., Palmer, R.M. and Pompei, P. (1998) Does Delirium Contribute to Poor Hospital Outcomes? A three Site Epidemiologic Study. Journal of General Internal Medicine, 13, 234-242. https://doi.org/10.1046/j.1525-1497.1998.00073.x

[10] Mercantonio, E.R., Ta, T., Duthie, E. and Resnick, N.M. (2002) Delirium Severity and Psychomotor Types: Their Relationship with Outcomes after Hip Fracture Repair. Journal of the American Geriatrics Society, 50, 850-857. https://doi.org/10.1046/j.1532-5415.2002.50210.x

[11] Ann, M.K., Nikki, L.H., Esra, K., Donna, M.F., Andrea, M.Y., Andrea, M.Y., et al. (2014) Gender Differences in Factors Associated with Delirium Severity in Older Adults with Dementia. Archives of Psychiatric Nursing, 28, 187-192. http://dx.doi.org/10.1016/j.apnu2014.01.004

[12] Inuoye, S.K. and Charpentier, P.A. (1996) Precipitating Factors for Delirium in Hospitalized Elderly Persons. Journal of American Medical Association, 275, 852-857. https://doi.org/10.1001/jama.1996.03530350034031

[13] Lipowski, Z.J. (1992) Update on Delirium. Psychiatric Clinics of North America, 15, 335-346. https://doi.org/10.1016/S0193-953X(18)30240-5

[14] Andersson, E., Gustafson, L. and Halberg, I. (2001) Acute Confusional State in Elderly Orthopaedic Patients: Factors of Importance for Detection in Nursing Care. International Journal of Psychiatry, 16, 7-17. https://doi.org/10.1002/1099-1166(200101)16:1<7::AID-GPS261>3.0.CO;2-W

[15] Aghanwa, H.S. and Morakinyo, O. (2001) Correlates of Psychiatric Morbidity in Typhoid Fever in a Nigerian General Hospital Setting. General Hospital Psychiatry, 23, 158-162. https://doi.org/10.1016/S0163-8343(01)00130-X

[16] Quinlan, N., Marcantonio, E.R., Inuoye, S.K., Gill, T.M., Kamholz, B. and Rudolph, J.L. (2011) Vulnerability: The Crossroads of Frailty and Delirium. Journal of the American Geriatrics Society, S2, S262-S268. http://dx.doi.org/10.1111/j.

[17] Philippe, V., Sylvie, R., Lise, D. and Pierre-Hugues, C. (2011) Factors Associated with Delirium Severity among Older Persons with Dementia. Journal of Neuroscience Nursing, 43, 62-69. https://doi.org/10.1097/JNN.0b013e31820b5fb6 


\section{List of Abbreviations}

A \& E: Accident and Emergency

CAM: Confusion Assessment Method

CVD: Cerebrovascular Disease

DSM-5: Diagnostic and Statistical Manual- $5^{\text {th }}$ Edition

DSR-R-98: Delirium Rating Scale-Revised-98

JUTH: Jos University Teaching Hospital

SPSS: Statistical Package for Social Science 